\title{
Relevance Of A Leadership Development Programme To Develop The Leaders' Work-Integrated Learning Competencies
}

Prakash Singh, Nelson Mandela Metropolitan University, South Africa

Christopher Malizo Dali, Nelson Mandela Metropolitan University, South Africa

\begin{abstract}
Today, more than ever, leaders need to demonstrate appropriate work-integrated learning competencies (WILCs) to process and manage emotional dynamics intelligently in their work environment. The challenge is to develop these leaders' WILCs that can enable them to understand the contextual environments and the power relationships among employees in their organization. This study, therefore, explored the extent to which WILCs, including their emotional intelligence, can be developed and employed in their organizations to enhance collegial leadership practices. Consequently, this study focused specifically on the adequacy of the Advanced Certificate in Education (ACE) school leadership (SL) programme as a leadership development programme (LDP) offered by a higher education institution (HEI) to develop the WILCs of school principals. The LDP is intended to provide the principals, as leaders, with the opportunity to develop a deeper holistic commitment to their studies in a working school situation. Ideally, the LDP would provide a basis upon which school principals acknowledge the complexity of learning across multiple epistemic sites, rather than from a reductionist view with university modules and schools as separate entities. To investigate this, the qualitative research approach was appropriately used in this study. The findings on the interpersonal WILCs revealed that the school principals acknowledged their awareness of their employees' feelings, needs and concerns and were adept at inducing desirable responses in them. Evidently, the findings of this study have confirmed the need for leaders to have interpersonal WILCs that can empower them to succeed in creating the necessary collegial climate in their organisations.
\end{abstract}

Keywords: Leadership Development Programme; Work-Integrated Learning Competencies; Collegial Leaders' Emotional Intelligence; Interpersonal Emotional Competencies

\section{INTRODUCTION}

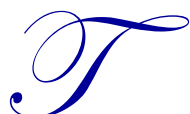

oday, more than ever, leaders need appropriate work-integrated learning competencies (WILCs) to process and manage emotional dynamics intelligently in the work environment. In this sense, one interesting direction to focus on is emotional intelligence (EI) that has recently become one of the most important constructs in leadership research, as is the case in this study (Nokelainen \& Ruohotie, 2006). The challenge is to develop the leaders' WILCs that can enable them to understand the contextual environments and the power relationships among employees in their organizations. Therefore, this study focused specifically on the adequacy of the Advanced Certificate in Education (ACE) school leadership (SL) programme as a leadership development programme (LDP) offered by a higher education institution (HEI) to develop the WILCs of school principals. The LDP is intended to provide the principals, as leaders, with the opportunity to develop a deeper holistic commitment to their studies in a working school situation. Ideally, the LDP would provide a basis upon which school principals acknowledge the complexity of learning across multiple epistemic sites, rather than from a reductionist view with university modules and schools as separate entities. It is expected that the principals participating in the ACE (SL) programme perceive that what they are learning in the lectures at HEIs is worthwhile and that it will lead to an improved disposition and capacity to excel in their demanding roles as collegial leaders. 
One of objectives of this LDP is to equip the principals and those aspiring to the post of principalship with current developments in education theory and practice (Mestry \& Singh, 2007). This practice-based two-year LDP seeks to provide principals with opportunities to interactively analyse situations and formulate strategies for tackling leadership and management problems in education (Mestry \& Singh, 2007).

Competent principals should realise that all socio-cultural, economic, political and civic aspects of the school exist in emerging and continuous dynamic processes of the school environment (Burkman, 2010). Ornstein and Hunkins (2004) argue that these dynamic processes can lead to information on which every leader has to reflect and act. Ornstein and Hunkins further argue that such information can be used in identifying new expectations, rewards and problems for those involved in the implementation process. Leaders can also use such information for identifying the emergence of new tensions that may create a state of disequilibrium among the employees. In turn, these tensions may set in motion an attempt by the stakeholders at schools to achieve a new state of equilibrium. This means that HEIs should address the need to develop the competencies of leaders, such as principals, to tackle emotional and social problems in their organizations (MacLean, 2006). This is a key concern, thus addressed in this study is the challenge for LDPs offered at HEIs to develop the WILCs of leaders so as to equip them to deal effectively and proactively with the rapid changes that face them in their organizations. HEIs are appropriately located to provide opportunities for principals to integrate their academic learning with practical implementation within the context of emotional and changing school situations. The HEIs and schools could work as epistemic sites whereby the interpersonal WILCs of school principals could be developed (Harris, 2006). Tennant and McMullen (2008) argue that competencies that school principals should learn include a combination of university teaching strategies and learning from the contextual school environment. In the school environment, principals are faced with emotional problems that include uncertain conditions of service, poor service delivery, teacher shortages, low morale of teachers, and a lack of physical and financial resources (Saiz, 2009). In addition to the emotional challenges experienced by school principals, Rees (2004) states that:

Within schools there are specific problems: parental interference, even litigiousness, over-regulation by authorities, spirited ennui, apathy, drugs, breakdown in discipline, vandalism, teacher shortages, laziness and lack of enthusiasm and the effects of HIV and AIDS. (p. 6)

This implies that there can be a disconnection between how principals are required to lead and accomplish their organizations' goals and the level of support they receive to meet expectations (Ketelle, 2008). This disconnection tends to affect the development of the competencies of principals that can help them to reflect on their leadership and to diagnose their own emotional strengths and weaknesses in their work environments. Hence, this study explored the school leaders' perceptions of their interpersonal emotional competencies that can link their academic studies with their learning experiences in the practical work environment (Baxter \& Burden, 2008). Since principals are occupying leadership positions in their schools, they are expected to demonstrate abilities to influence, motivate and enable teachers, parents and learners to contribute to the effectiveness and success of the schools of which they are stakeholders (Anand \& UdayaSuriyan, 2010). As education becomes more complex, both in structure and purpose, the principals need EI to effectively work with their colleagues. They have to effectively perceive, express, understand, and manage their emotions and the emotions of learners, parents, and their staff in a positive and collegial manner. Recent research examining the utility of EI in promoting effective leaders emphasizes the significance of EI in the organizational environment (Anand \& UdayaSuriyan, 2010; Barbuto \& Burbach, 2006; Dulewicz, Young \& Dulewicz, 2005; Gardner \& Stough, 2002). Leaders with EI are perceived to be happier and more committed to their organizations (Abraham, 2000). They use their emotions to improve their decision-making and instil a sense of enthusiasm, confidence, optimism, adaptability, empathy, and collegiality with their staff members through interpersonal relationships (Singh, 2013; George, 2000). Principals need to demonstrate the necessary emotional competencies of leadership, communication, conflict management, relationships, and trust in order to assist in the creation of a collegial work environment (Singh, 2013; Calitz, 2002). Such competencies should assist principals to be aware of and manage their emotions and those of the people in their work environment so that they may develop collegial relationships. This study, therefore, focused on the leaders' perceptions of the relevance of LDP to develop their WILCs. 


\section{Interconnectedness Between WILCS And EI}

This study explores the extent to which WILCs and EI can be utilised to enhance collegial school leadership and to develop principals' capabilities to share knowledge and creatively solve problems at their schools. EI refers to creative behaviour and an array of capabilities and competencies that influence one's ability to succeed in coping with environmental demands and pressures and the cognitive ability to regulate one's emotions to reduce negative emotions and to maintain positive emotions between self (intrapersonal) and others (interpersonal) (BarOn, 2000; Mayer, 2001; Mayer \& Salovey, 1997). Understanding the interconnectedness between the WILCs and EI for the effective collegial leadership of principals is crucial. In this study, it is argued that the WILCs of school principals are pivotal in collaborative and shared decision-making of school leaders. Lopes, Brackett, Nezlek, Schutz, Sellin and Salovey (2004) affirm that competencies based on EI are important for intrapersonal and interpersonal interactions because emotions serve communicative and social functions. This suggests that as leaders work and learn from their experiences, their understanding of EI would empower them to manage their emotional responses to the challenges they face, ensuring that their feelings are expressed appropriately and effectively to encourage collaborative relationships in their organizations.

The international reference to the concept of WILCs, according to Groenewald (2004), is to give a new meaning to the notion of cooperative learning and the concept interchangeably uses terms that have similar (or lesser) meanings, such as practice-oriented education, professional practice, project-based learning, sandwich degree/course, learning and work experience. The concept WILCs is inherently experiential and developmental since students are given an opportunity to apply what they are learning as they are learning it in their occupational fields (Groenewald, 2004). This suggests that the concept WILCs provides progressive experiences in integrating theory and practice. The integration and logistical coordination and assessment of the experiential and academic parts of curriculum development include partnerships between the student, the institution, and their contextual work experiences. For the purpose of this study, the concept of WILCs is utilised to describe the emotional and cognitive competencies that principals could develop to be effective in their leadership practices at their schools. This investigation was based on the foundations of EI and its connectedness to the WILCs of school principals. Although the terminology and approaches of various authors may differ, their common denominator can be identified in the findings of Goleman that extend the application of the EI construct into the leadership arena (Goleman, Boyatzis \& McKee, 2002). The EI construct is important in this framework since it is inherent to the practice of leadership rather than separate from it. Crawford (2007) aptly points out that it is not enough for leaders to acknowledge the inherent emotions in the culture of an organisation; they have to make them explicit through their own leadership.

While management is objectives-driven, resulting in stability based on rationality, bureaucratic means, and the fulfilment of contractual obligations, leadership is, according to Alves, Manz, and Butterfield (2005), considered to be purpose-driven, resulting in change based on values, ideals, vision, symbols, and, most importantly, emotional exchanges. This means that while the leaders coordinate, define purpose, and anticipate, the essence of leadership is to teach others how to handle conflict in a collegial manner. This affirms that leadership is not only how it happens in practice - for example, through communication - but also how that practice is framed by people's emotions, theoretical principles, and the contextual environment. Cooper (1984) points out seven potential sources of conflict that leaders can face in their organizations:

- $\quad$ Organizational Change: One of the sources of conflict is that employees are interested in traditional ways of doing their work because those ways have become part of them. Changes would require much effort and adjustment.

- $\quad$ Personality Clashes: Not every employee thinks, feels, looks, acts, or works in the same way. Each one has a unique personality. Employees need to respect each other's differences, accept people the way they are, and learn how to use these differences for the common good of the organization.

- $\quad$ Different Sets Of Values: Employees also hold different beliefs and adhere to different value systems. This can be due to diverse culture, tradition, and philosophies. Again, respect and acceptance are very necessary among employees.

- $\quad$ Threats To Status Quo: An employee who feels threatened is always defensive and can create conflicts within the organization.

- $\quad$ Contrasting Perceptions: Employees perceive things differently as a result of their prior experiences and 
expectations.

- Lack Of Trust: When someone has a real or perceived reason not to trust another, the potential for conflict arises.

- Miscommunication: This is due to language and environmental factors such as space, noise, location, and facilities. (pp. 314-315)

The notion that the WILCs are crucial for adaptation in various realms of life has increased interest in the concept of EI and inspired a variety of programmes of both emotional and cognitive learning in educational institutions and work settings (Lopes et al., 2004). In order for leaders to effectively utilise their WILCs, understanding how EI works becomes crucial, especially since school principals have to work with different people with diverse emotional dispositions. Principals have to understand their own emotions in order to understand the emotions of the people they work with in their schools. Crawford (2007) asserts that:

Emotional relationships are the core, not just about any school-related work, but are pivotal to the concept of educational leadership. At the centre of a school lie relationships: teacher-student; parent-teacher; teacher-teacher; child-child. These relationships may be many and different, but they are quite literally at the heart of education. (p. 522)

Studies to date have demonstrated that leaders who report higher levels of EI also report higher levels of attending to positive interactions with those with whom they work (Ivcevic, Brackett \& Mayer, 2007). Other studies have found a significant interconnectedness between the WILCs required in the development of leaders, such as principals, and EI (Schutte, Malouff, Bobik, Coston, Greeson, Jedlicka, Rhodes, \& Wendorf, 2001). Bar-On (1997) also asserts that EI evokes the emotional, personal, social, and survival dimensions of intelligence, which are often more important for daily functioning than the more traditional cognitive aspects of intelligence. He further clarifies that EI is concerned with understanding oneself and others, relating to people, and adapting to and coping with the immediate surroundings to be more successful in dealing with environmental demands, "in a way, to measure emotional intelligence is to measure one's common sense and ability to get along in the world." (p. 1)

The role of the ACE (SL) programme, to assist principals to tap into their EI so as to develop WILCs in relationships that correspond to those in their schools, has become crucial. This implies that EI can form an emotional bond that can help school principals stay focused even amid profound change and uncertainty in their school leadership positions (Singh, Manser \& Mestry, 2007; Goleman, Boyatzis \& McKee, 2002). Understanding how to cultivate competencies in EI is essential for the development of school principals' WILCs. Hang (1999) suggests that the link between work-related competencies and EI be:

...advantageously used to fine-tune on-the-job performance of every kind, managing our unruly feelings, keeping ourselves motivated, tuning in with accuracy to the feelings of those around us, and developing good work-related social skills, including those essential for leadership and teamwork. (p. 7)

Yukl (2002) further points out that:

Emotional intelligence can help leaders solve complex problems, make better decisions, plan how to use their time effectively, adapt their behaviour to situations, and manage crises. (p. 197)

Singh, Manser and Mestry (2007) suggest that for school principals to be seen as effective leaders, they need to combine intellectual brilliance (IQ) with EI. These authors argue that in the evermore difficult leadership role, EI can provide developing leaders with a competitive edge. This view is supported by Gardner and Stough (2002) who state that:

The ability of the leader to identify and understand the emotions of others in the workplace, to be able to manage their own and others' positive and negative emotions, to be able to control emotions in the workplace effectively, to utilise emotional information when problem solving and to be able to express their feelings to others is integral to the leader being effective at creating appropriate levels of job satisfaction. (p. 76) 
Learned WILCs can help principals to cope with environmental demands and pressures at their schools. Mayer, Salovey and Caruso (2004) argue that people with high EI can better perceive emotions, use them in thought, understand their meanings, and manage emotions better than others. Principals who are able to demonstrate such WILCs tend to be more open and agreeable than others (Mayer et al., 2004). Such principals are less apt to engage in problem behaviours and avoid self-destructive behaviours. HEIs are appropriately located to provide opportunities for such leaders to integrate their academic learning with practical implementation within the context of emotional and changing organizational situations. The space for integrating learning and work competencies can be found within the connections that develop between these two epistemic sites. The space is facilitated by interactions and interrelations that are complementary to both these two epistemic sites. It is the crossover points of interactions and interrelations between these two epistemic sites that highlight the importance of bridging the gap between theory and practice in knowledge creation (Eames \& Cates, 2004). Effective collegial leaders could then link organizational goals to the emotional needs and concerns of their employees (Sarros \& Sarros, 2007). Due to the complex environment in which principals have to operate, this study therefore addressed key concerns of WILCs and EI in order for school principals to succeed as collegial leaders.

\section{RESEARCH METHOD}

\section{Qualitative Research Approach}

The qualitative research approach was used in this study. Semi-structured interviews were used to elicit responses from the respondents. The research methods used were comprised of five focus group (FG) interviews with ten principals in each group, as well as ten single in-depth interviews. The latter was referred to as In-Depth 1 to In-Depth 10 in order to protect the identity of the participants. Purposive, rather that random, sampling was employed since this study required depth and richness of the data obtained from the participants (Stead \& Struwig, 2001; Miles \& Huberman, 1994; Morse, 1994). Also, purposive sampling was used because of the accessibility and availability of the research participants. The research participants consisted of sixty principals doing the ACE (SL) programme at an HEI.

The in-depth interviews created opportunities for all research participants to be comfortable with sharing some of their experiences and perceptions in a focus group. Each in-depth interview lasted about an hour and it created an adequate room for a detailed conversation with each interviewee (Ehigie \& Ehigie, 2005). The FG interviews were selected as one of the research methods for collecting data since they provided a context for the research participants to articulate the meaning of their experiences and elaborate on them in a collective sensemaking process (Heiskanen, Jarvela, Pulliainen, Saastamoinen \& Timonen, 2008). Fer (2004) states that a focus group is a semi-structured method of group interviewing designed to yield contextually rich information about a topic in an efficient and quick manner. The duration of each FG interview was two hours. This paper focuses only on a section of the research conducted on the EI of leaders; hence, the focus of this paper is on the interpersonal skills of leaders that is associated with their adeptness to induce desirable responses in their employees.

The research participants and their institutions were assured of privacy and confidentiality and they gave informed consent to record the interviews (Lankshear \& Knobel, 2004). It was also necessary to ensure that the research participants were protected against any emotional or physical discomfort from the research process (Dane, 1990). It was confirmed that the research participants were not misrepresented or offered incorrect information in order to ensure their participation (Corey, Corey \& Callanan, 1993). Thus, assurance was given that they could withdraw whenever they wished to. Ongoing access to the research participants was negotiated and maintained by securing permission from the HEI, the institution where they were registered for their ACE (SL) studies (Devers \& Fraenkel, 2000). Written consent was secured from the participants for the interviews. In this study, qualitative research reliability was used for the purpose of generating understanding of the value of interpersonal skills as WILCs for school principals (Stenbacka, 2001). Validity was established by utilizing quality, rigour and trustworthiness for the purpose of establishing confidence in the findings (Davies \& Dodd, 2002; Stenbacka, 2001). 


\section{DISCUSSION OF THE FINDINGS}

The following seven themes or sub-categories were identified from the responses of the participants in terms of their interpersonal WILCs to induce desirable responses in their employees:

- $\quad$ The first sub-category is about the influence of school principals as leaders.

- The second sub-category is on communication and its focus includes listening openly and sending convincing messages.

- $\quad$ The third sub-category deals with conflict management.

- $\quad$ The fourth sub-category is about leadership competency and it focuses on data representing the ability to inspire and guide individuals and groups.

- $\quad$ The fifth sub-category is on school principals as change catalysts. It focuses on initiating and managing change.

- $\quad$ The sixth sub-category is on building bonds and it represents data on nurturing instrumental relationships.

- $\quad$ The seventh sub-category is on collaboration and teamwork. It focuses on leaders working with their employees toward shared goals and creating group synergy in pursuing collective goals of their organizations.

These sub-categories are analysed below in terms of the research findings.

\section{Influence}

This sub-category represents data on the ability of school principals to wield effective tactics for persuasion. It involves the ability to motivate and enable others to contribute to the effectiveness of the schools of which they are members. For example, FGs pointed out that:

In order to influence educators, school principals should sometimes meet with them individually and get their opinions on what needs to be done. By the time we meet with the whole group, it becomes a matter of formality because we have assessed the situation and if we have certain individuals who have different opinions, we can address those issues first so that at the end we have a common understanding.

The response showed that the school principals knew how to get inside the teachers to work with them by emphasizing free will and driving out the inner doubts their teachers might have had. In this way, the principals could assess and touch the mindset of their teachers and enable them to develop new steps in their commitment levels for reaching a common understanding within their schools.

In-Depth 1 corroborated the above view by stating that:

I think I'm good in that one, insomuch that at times I keep quiet when I want them to be open and talk. What normally happens is that I discuss a situation before they come to a solution or a conclusion. If I make an input, they take that as what has to be done. So, if I want their opinions, I'll rather keep quiet.

The principal introduced new processes at the school by anticipating and influencing the way the teachers thought. In this way, the principal influenced the teachers by understanding their cognitive and emotional perceptions and by facilitating open discussions and comprehension of the situation. Salmon (2008) states that the ability to envisage possible alternatives is a crucial quality of thinking that leaders increasingly need in this millennium. Not only did the school principal demonstrate the ability to anticipate, but was also able to effectively respond to the teachers' emotions and thoughts by capitalising on them for positive future development at the school.

In-Depth 2 concurred with the above responses by stating that:

You know, sometimes if there are issues that are controversial that are to be discussed, I call the staff members to me one by one. I engage with them in small groups; get to know and understand them and their concerns on the 
topic. I address those issues in small groups in a positive atmosphere, not just throwing these issues at a big group without meeting before. If I go to the staff meetings, normally I find that many people are in an argument with me already. So, if there are some people I've missed out, then there will be those people who will explain to others, not me sometimes.

In order to handle and manage emotions effectively in other stakeholders at school, the principal had to sense the teachers' reactions and fine-tune their responses to move interaction in the best direction. For example, one school principal mentioned that:

My weakness is that sometimes I become impatient. Even though I listen to people's ideas sometimes, I tend to impose my ideas or feelings on them. I think that is my weakness.

This response indicated that although the school principal was aware of the need to understand the emotions of others, he tended to use coercion instead of using influence in a positive manner. However, the feedback from the in-depth interviews and the FGs generally indicated that the school principals respected the opinions of others in developing mutual relationships and interdependence at school. Strategies adapted included opening space for others to voice their opinions, discussing issues with a few individuals first for consultation purposes, and allowing those few individuals to take the initiative of persuading others at broader staff meetings. The responses of school principals indicated that they did have some ability to persuade and to utilise complex strategies, like indirect influence, to build consensus and support. The responses of the school principals showed that they understood how to orchestrate and dramatise events to effectively make a point. This meant that with developed EI, the school principals would have a positive impact on the quality of their decisions. Most of the school principals seemed to be fully aware that increased competency in wielding influence is built on both managing their emotions and enhancing the harmony at their schools.

Influence develops healthy conversations by being attuned to others' emotional states and controlling the impulse that might spoil the emotional climate. However, the responses also indicated that some principals might still require more fine-tuning abilities to be effective leaders in their schools. This meant that the ACE (SL) programme had to sharpen the principals' influence competency so that they could become fully effective in the give-and-take of emotional information. Effectiveness in the competency of influence can lead to the principals' ability to use motivation and decisiveness that can energise their staff and drive them towards achieving goals of the school.

\section{Communication}

This sub-category on communication represented the ability of school principals to listen openly and send convincing messages. In this regard, In-Depth 5 stated that:

The ability to communicate as a school principal goes a long way. There is nothing that surpasses listening when you communicate; so then you value the opinions of others. If you begin by allowing them to speak, you create a platform whereby ideas are reflected upon, shared and valued.

The school principals concurred that the communication competency was essential for building consensus, motivating others, building confidence in others, and acknowledging their opinions. The FGs stated that:

As the leaders and the managers of our schools, we use different approaches of communication. We use instruction books for notices. We use formal meetings in the morning on Mondays, Wednesdays and Fridays. These are briefing sessions of ten minutes before school starts. We use e-mails to motivate the teachers and learners. Sometimes there are no issues coming from the principal's offices, but we just motivate one another to build our confidence by acknowledging our inputs in various aspects.

The principals utilised all the strategies they knew to listen, communicate, and motivate others in order to reflect and share ideas for the development of their schools. For example, In-Depth 7 pointed out that: 
When I give a message, I try to give a clear message. When there is a difficult situation, I control my emotions so that my communication contributes to solving problems at school. I always seek mutual understanding by fostering open communication and accepting both good and bad news. I use a professional approach in communicating with other people.

It became evident that the school principal had to utilise different tactics in order to solve problems at school and to cope with the complex and emotionally-draining work environment. The account revealed that the principal's ability to manage emotions and the ability to facilitate flexible focus on attention proved effective for smooth communication and interpersonal interaction. For the purposes of implementing the communication competency, one school principal pointed out that:

To be clear about procedures in our school, we have an agreed upon policy on communication. In this way, we are trying to avoid a state of limbo among educators and learners.

The response indicated that the ability to create an atmosphere of openness with clear lines of communication was perceived by the school principal as important to motivate the teachers and learners. The school principal used the communication policy as a tool to ensure that the messages conveyed were appropriate and effective within the school context. Another principal agreed with the above response by stating that:

I have learnt more about the power of communication in an organization. This area can cause a lot of confusion if not properly managed both internally and externally. This refers to verbal and written communication strategies and the ability to listen with emotional understanding of all the stakeholders at my school.

This response showed that the school principal viewed the communication competency as a means of showing understanding and feelings for others. Payne (2005) asserts that listening and empathising are ways of being an attentive communicator. A leader with a high EI demonstrates interest in and attention to others in conversations. Communication, in this sense, involves adapting emotional messages, listening and conveying supportive and empathetic messages (Payne, 2005). Emotionally intelligent school leaders will also listen to the viewpoints of representatives from all departments of their schools and consider them when making decisions. Generally, the responses from the in-depth interviews and the FGs indicated that in order to achieve communication goals, the school principals had to develop knowledge to construct action plans, often referred to as communication scripts (Payne, 2005). The responses of the principals indicated that they had procedural knowledge to construct and act out those scripts by connecting emotionally with all the stakeholders at their schools. Ketelle (2008) argues that as the competency of communication develops, leaders become reflective in their thinking as well. It thus became evident that principals had to articulate clearly who they were and what they believed. By implication, this means that school principals who have the ability to interact with their teachers using the communication competency based within the underpinnings of EI could greatly affect the overall learning and teaching environment in their schools (Ayiro, 2009).

\section{Conflict Management}

Conflict management involves negotiating and resolving disagreements. Conflict management focuses on competencies to build good relationships, to minimise the risk of conflict, and to deal with it in a constructive manner. In-Depth 7 stated that:

About conflict management, I normally assess my performance and that of other people who come into my office with conflict to be resolved. My measurement of success is when they go out of my office happy or unhappy. If they leave my office unsatisfied and with tensions, then I know that I have not succeeded. If they leave my office with smiles and holding hands, then I know that I have resolved it.

This response indicated that the school principal perceived successful conflict management as understanding and analysing conflict with the view of arriving at amicable solutions. This view was corroborated by the response of In-Depth 3, who stated that: 
What I normally encourage is that the two parties should come together and try to look at what is happening without pointing fingers at each other.

This pointed directly to the high EI required by principals for sustaining harmonious interactions among the stakeholders in their schools. In-Depth 10 pointed out that:

Conflict will always be around us all the time. What we need to do as school principals is to manage it. In practical terms, we need knowledge of conflict management and the ability to apply conflict management strategies.

This response indicated that the principal was aware that as long as there is a human element present at school, conflict is inevitable and should not be avoided. This implied developing appropriate strategies for solving the conflicts and maintaining stability of the school. The FGs agreed that:

The intention of solving conflicts at school should be to direct all energies toward developing stability instead of exacerbating tensions by ignoring or using delaying tactics. The intention should be to bring conflicting parties closer than ever before. It should also be to make people understand the benefits of solving conflicts amicably. Teachers need to know that, at the end, we need to work together and respect one another as colleagues.

This response revealed that the school principals perceived appropriate conflict management as emanating from interaction that achieves the valued objectives for both the conflicting parties and their schools. This meant that school principals had to develop competencies and knowledge on how to manage conflict as effectively as possible when the inevitable conflict surfaced. The response suggested that the competency of conflict management was to ensure respect, dignity, reconciliation and collegiality among teachers so that they might work toward a shared vision of their school. However, not all the school principals were comfortable with their abilities to handle conflict situations. A concerned principal revealed that:

I'm not a conflict manager and I don't want to be always involved in solving conflicts. The HODs are there to help me, especially in minor cases. However, it would appear that the problems come both from outside and from within the school premises. Some people are arrogant and do not see themselves as people who can make mistakes.

This response suggested that the school principal used various strategies, such as trying to identify the root causes of conflicts and delegating senior members of staff to assist in resolving some of the conflicts. The response further indicated that conflicts at school sometimes come because of internal and external factors. Hence, the school principals needed a programme such as ACE (SL) that could help them to develop their interpersonal WILCs for resolving conflicts. Another school principal added that:

Most principals lack the necessary conflict management skills to solve problems with parents, between learners and educators, and this affects the effectiveness of the principal to create a harmonious environment that is conducive to learning and teaching.

This view was corroborated by another school principal who stated that:

In conflict situations, I need to sharpen my skills to be neutral and impartial and try to find the causes of the conflict and treat the parties with respect and listen attentively to find alternatives and best solutions.

The FGs suggested that:

Principals should not ignore disputes since they create hatred and sometimes cold wars. Conflict must not be avoided as it empowers us to solve problems and to know one another. The ACE programme can assist principals to learn how to handle disputes. Principals must learn to be straight forward and outspoken when dealing with conflict, but on a positive note. Principals must try to offer a creative atmosphere all the time. They must learn to understand that people are the most valuable assets. 
Feedback from the in-depth interviews and the FGs seemed to concur that when properly managed, conflict could bring colleagues together by creating an atmosphere whereby collective work in the true spirit of collegiality could be done for the good of the school. Conflict management was viewed as crucial for long-term collegial relationships at school. The analysis of the responses from the data also indicated that the competency to overcome conflict with colleagues by negotiating and influencing their moods and emotions was something that the ACE (SL) programme could enhance when developing school principals' WILCs.

\section{Inspirational Leadership}

Inspirational leadership involves the ability of leaders to motivate their employees to aspire towards attaining high performance. It includes the ability of the leader to make emotional connections with their employees by inspiring them to become passionate about what they are doing. For example, the FGs agreed that:

Principals are in a leadership relationship with many people in their schools. In order to develop this relationship to its fullest potential and thus get active involvement of staff, parents, learners and community members in the governance of the school, it is necessary for principals to make sure that they understand the emotional needs of the teachers. This will help them to achieve the goals of their schools.

The responses from the FGs showed that the school principals were aware of the value of creating a vision that would inspire the school community to get committed about both their development and the growth of their schools. The FGs also agreed that:

Principals should make sure that there is an ongoing professional and personal growth at the school by shaping the vision of the school with other members of the school and by motivating and inspiring them to do their best.

The principals valued the social-constructive, integrative and inspirational approach to address the needs and concerns of their employees and other stakeholders within the context of collective engagement. This meant that the principals' development of their WILCs in the ACE (SL) programme encouraged their positive understanding of their employees' and stakeholders' emotional needs in the achievement of their professional development and the growth of their schools. When inspiring others, In-Depth 1 pointed out that:

When I motivate the teachers, I like to acknowledge their achievements. This encourages them to do more. In acknowledging their achievements, I concentrate on their strengths with the intention of empowering them to do more on their own and to improve on their weaknesses.

This response indicated that the school principal inspired the staff by showing concern and passion for what they were doing. This pointed at the principal's ability to energise the teachers to become more empowered and autonomous. One principal concurred with this point of view by stating that:

When you show your teachers passion and enthusiasm as a leader about the mission and vision of the school, they, too, become passionate and inspired to follow you and contribute towards the implementation of that mission. You have to motivate them in that way as the principal of the school.

In-Depth 2 concurred by stating that:

I think I should inspire my staff by recognizing their potential and achievements and praise them by giving them a pat on their backs. I must inspire those who don't reach their goals because there's still time to learn. They need to be inspired so that they get involved in all the school activities.

The responses also indicated that inspirational leadership, as an organizational quality, included teachers' participation. In this regard, In-Depth 4 stated that:

The ACE programme has helped me in shaping the character of my school leadership. I always wanted to revisit my leadership approach and inculcate a culture of love. Therefore, I became creative in getting things done by motivating the staff, parents, and learners. 
The responses from the in-depth interviews and the FGs indicated that the school principals' level of EI was at an acceptable level when it came to the ability to inspire their colleagues. The responses indicated that the LDP was a necessary intervention to develop the principals' WILCs to get their employees enthusiastic and involved in realising the mission and vision of their organizations.

\section{Change Catalyst}

A leader, being a change catalyst in the organization, involves the ability to initiate and manage change. Change catalysts create an organizational climate that fosters participation by all stakeholders in the development and change processes of their organization (Singh, 2005). For instance, In-Depth 2 stated that:

I believe that if you want to see change in your school, you must tell people why it is necessary to change, why they have to change from what they are used to doing, what are the benefits of change, what are the challenges of that change. In that process, I normally engage them. I call them in and discuss the changes intended for the accomplishment of the school's objectives.

The principal seemed to value the tensions and difficulties inherent in addressing school change. The principal demonstrated the ability to help the staff to come together, accept, embrace and do all they could to create change and drive it. The ability to successfully engage organisational members in change initiatives is one of the fundamental competencies of a leader (Gilley, McMillan \& Gilley, 2009:38). Leaders who are high in EI are able to build relationships, especially when they are aware of their own emotional makeup as change catalysts (Goleman $e t$ al., 2002). On this issue, In-Depth 9 stated that:

In many cases, change comes because of a problem or a barrier that you have in your school. Then we would discuss that barrier, everyone would be aware of that problem, and then we would possibly find some solutions. I have also used what is called the problem tree approach that we've learnt here in the ACE (SL) programme. We discuss various solutions because too many people rebel against change. One needs to read about it so that everyone understands the reason behind the required change and goals of the school.

Another principal believed that:

Change is always necessary in order to improve any situation. I have learnt that change, though positive, is not easy to accept. The strategies and tactics we learnt as school principals coming from the different backgrounds during the ACE (SL) programme, and through the case studies presented by us coming from different schools, and the group discussions in the ACE programme, empowered me a lot in managing change.

The above responses suggested that the LDP allowed the leaders to discuss different case studies relating to change management. This linked to the learning outcomes of the LDP which emphasized the need for school principals to engage with challenges and issues in their organizations. The above responses also indicated that although managing change could be difficult, the ACE (SL) programme provided the school principals from urban, rural, and farm schools in the discussion groups with opportunities to share, compare, and contrast their change strategies. The FGs agreed that:

In the ACE programme, we have learnt to allow people to challenge us. At first it did not go down so well, but as we allowed many voices, we began to pick up constructive ideas from them as well. In this way, we are now able to develop our staff for change. We understand their strengths and weaknesses. They can help us with the development of the school change policies. Now this is how we encourage organizational change.

This response showed that the school principals valued the need to look at the way they came across to other school members, identify their strengths and weaknesses, and overcome emotional blind spots in their leadership styles. This implied that the school principals could create change and develop policy while emotionally empowering their teachers (Catano \& Stronge, 2007). A principal shared his experiences about this interconnectedness between the change competency and EI by stating that: 
I must confess that when I got the appointment as a principal at my school, I felt intimidated by my staff. It was easier for me to isolate myself in my office and communicate via written notices. The ACE programme is highly appreciated because it helped me to encourage my educators and to prepare them emotionally for the rapid changes taking place in our schools. However, I must honestly admit that I am still struggling to change the attitude of some educators.

The feedback from the in-depth interviews and the FGs revealed that principals acknowledged that their staff had different capabilities that could be harnessed for change processes. School principals had to make sure that their staff understood what needed to be changed and that they were all motivated to participate in the discussionmaking processes leading to change. In the process of developing as change catalysts, the principals involved themselves by getting commitment from their employees who might not necessarily like their leaders' approach to implement change. These leaders were providing their employees with collegial support to assess and find collective meaning and commitment to new ways of doing things in their organizations. It became clear that a major factor common to successful change was that emotional relationships among all the employees had to improve first.

The accounts showed that the principals were prepared to accept emotional exchange and different opinions from their staff members. From the above accounts, it could be inferred that the competency to respond to rapid shifts in school environments and the ability to effectively access EI competencies transcend the spectrum of leadership (Ayiro, 2009). Thus, when developing WILCs of school principals, it would be helpful for the ACE (SL) programme to encourage emotional understanding of the nature of the context into which changes have to be introduced. When the principals are emotionally aware of their work environments, they can respond appropriately to events and situations at their schools (Gardenswartz, Cherbosque \& Rowe, 2010). Ayiro (2009) argues that principals who are able to respond quickly and effectively to dynamic environments and are able to implement the necessary changes have been most successful in the development of their staff and sustained long-term growth and cohesion in their schools.

\section{Building Bonds}

This category focuses on principals' perceptions and experiences on building bonds as a competency in cultivating and maintaining extensive informal networks and seeking out relationships that are mutually beneficial to their schools. This involves the ability of school principals to build rapport among their staff and keep them in the loop while making and maintaining personal friendships. In-Depth 2 stated that:

When building good relationships with the people we work with as school principals, we have to start with the fundamental values like respecting one another, accommodating one another, accepting one another, and understanding our limitations and strengths. Another thing that I normally do at my school, as a leader, is to give credit where and when necessary. I think these things create bonds and bridges between people for further achievement and growth for the school.

This response suggested that the school principal valued the need to create good feelings among the teachers. The creation of positive emotions was to bring out the best in staff by causing them to become excited about the good things they had done and to make them feel like doing more for the school. In-Depth 7 concurred by stating that:

Working together towards achieving a common understanding is a powerful way of building bonds among stakeholders.

This response suggested that building bonds contributed to positive interpersonal relationships. Goleman et al. (2002) argue that the glue that holds people together and that commits them to their organization is the positive emotions they have. In-Depth 4 agreed with the above statement by pointing out that:

Building bonds with the staff is a process. It requires that I first open up so that I can be accessible to the staff and that they may feel free to use their talents. These little things build good working relations in a school. 
The response indicated that the principal was prepared to cultivate and sustain a network of relationships with the staff by opening up to them first. This emotional alignment was to create a resonance that would move the staff emotionally as well as intellectually. The FGs agreed that:

As school principals, we should build bonds by working hand in hand with others, and the problems we get at our schools should bring us closer together so that we may meaningfully and intellectually face them as one big family.

One principal argued that:

The principal, the SMTs, the learners and parents, should all maintain sound relationships in order to reach goals that bind us together at school. This will take off the stress of having to meet the demands and deadlines of the DoE.

The feedback from the in-depth interviews and the FGs suggested that the competency of building bonds requires that all the stakeholders at school be aware of the impact their emotions play on the effectiveness and success of their schools (Luca \& Tarricone, 2001). The above accounts revealed that building bonds as a competency could lead to common emotional understanding and intellectual commitment among the school stakeholders. Thus, the ACE (SL) programme could further help the principals to manage their emotional responses to the challenges they face and ensure that their feelings are expressed appropriately and effectively to create emotional bonds and harmony with teachers in their schools.

\section{Collaboration And Teamwork}

This sub-category involves the ability to create harmonious relationships that encourage individuals to collaborate with the team in order to generate mutually beneficial ideas and solutions (Maxwell, 2010). This means that competencies of collaboration and teamwork involve working together with others toward shared goals and creating group synergy in pursuing collective solutions. It also involves the ability of leaders to get things done with their employees. In response to questions around the competency of collaboration and cooperation, In-Depth 3 stated that:

Collaboration at my school is very important. In order to achieve collaboration, I encourage my staff to respect one another. In this way, we can all respect one another's ideas and work as a team.

The response indicated that the school principal perceived respect as pivotal to enhance collaboration and cooperation at the school. The principal viewed leadership activities as collective construction processes rather than individual endeavours. Respecting others led to sharing their ideas. In-Depth 2 supported the relevance of respect in the process of developing the collaboration and cooperation competency by stating that:

Mutual respect amongst people is important because it's no use thinking of building good relationships when people don't behave and have a disregard for others. Therefore, we have to start with the fundamental values, such as respecting, embracing, and accepting one another, and understanding our limitations and strengths. In this way, we create bridges between people for further achievement and growth for the school.

The response indicated that collaboration and cooperation had a potential of enhancing school growth and the achievement of goals. Mutual respect and emotional acceptance among colleagues enhanced the acknowledgement of colleagues' limitations and strengths for the purpose of collective development and school growth. This also made cooperative work easier. In-Depth 8 concurred that:

The ACE programme has helped me to realise that working together at school enhances my understanding of my staff members' emotional needs as we collectively plan together for school improvement and school development.

The response indicated that the leaders' recognition of their employees emotional needs could enhance collaboration in improving their schools. Due to the discussions among the school principals during the ACE (SL) programme sessions, school principals were able to share ideas and perspectives on collaborative and cooperative work at their schools. One school principal endorsed this view by stating that: 
Through the help of the ACE programme, I managed to secure the support and high involvement of the SGB (School Governing Body) in the school's development. Together with the SGB, we managed to revise the school's vision. We further adapted a School Improvement Plan and the Staff Development Plan. What I discovered from other school principals in the ACE programme was how the school principal could take on board teachers, parents, and other interested parties in effective curriculum planning and implementation, and all the issues related to Integrated Quality Management Systems based on consultation and cooperation.

The response indicated that the ACE (SL) programme did encourage the school principals to work with all the stakeholders at school. One principal stated that:

As a result of the ACE programme, I realised that the SMTs (School Management Teams), SGBs, teaching, and nonteaching staff should be given a chance to explore their expertise. When teachers are part of the solution, vision, and mission, they eagerly contribute toward the collaborative implementation of decisions at the school.

The school principal encouraged active participation of all the stakeholders in the decision-making processes of the school. During the FGs, the school principals agreed that:

Governance should be seen as co-operation and partnership to bring about positive educational outcomes through collegial leadership. Stakeholder relationships and teamwork are therefore very important to the task of leading and managing in schools.

In-Depth 10 added that:

Working together and using collegial leadership have advantages: people discover common needs and purposes; they see a connection between their own needs and the school's needs; people feel that they are doing something that matters to them personally and to their larger team; and people welcome problems which are challenging and through which they will grow and learn as a team.

Working together as a team meant that the school principal and the staff would be able to empower one another in their development. By encouraging collegial relationships, the principals were simultaneously creating a conducive environment in which emotions of everyone would contribute to individual and team development. Singh (2010) points out that emotions are contagious and that a single person can influence the emotional tone of a team by modelling. The accounts from the in-depth interviews and the FGs indicated that the school principals were sensitive to the emotions of their colleagues and wanted to ensure that their participation would create an atmosphere where everybody would feel accepted to contribute their ideas in their school teams. Prati, Liu, Perrewe and Ferris (2009) affirm that the possession of EI is regarded as a potentially valuable asset for organizational members, especially in terms of teamwork.

From the above accounts, it emerged that the school principals valued the EI competency of collegiality, especially as the ACE (SL) programme encouraged them to focus on the stakeholders' capacity to play a participatory role in the leadership of their schools. Singh, Manser and Mestry (2007) believe that collegiality, as an EI competency, entails the devolution of power to educators. It also entails, on the part of those involved, being actively involved in their school development, problem-solving, and being responsible and accountable for creating positive teamwork relationships, commitment, and a drive for improvement.

\section{CONCLUSION}

The findings of this study strongly suggest that the ACE (SL) programme, as an LDP, was successful in developing the WILCs of school principals as collegial leaders of their organizations. This implies that leaders and their employees must become accountable and responsible for the outcomes that emanate from decisions made jointly. Evidently, the findings of this study have confirmed the need for leaders to have interpersonal WILCs that empowers them to succeed in creating the necessary collegial climate in their schools. The finding on the interpersonal WILCs revealed that the leaders acknowledged the awareness of their employees feelings, needs and concerns. They were adept at inducing desirable responses in them. The findings further denote that the LDP can 
provide the leaders with exposure to various strategies that include initiative, persuasion, teamwork, collaboration, and building bonds - WILCs that lead to the development of collegial leadership. This exposure resulted in a sense of commitment, encouraged the leaders to persist - even in times of setbacks, and allowed for the development of individual potential and collective organizational growth in a more conducive work environment. The relevance of the findings of this study links clearly with the demanding and complex interconnectedness between WILCs and EI that leaders have to demonstrate in their organizations. Collegial leadership can be perceived as a particularly emotion-laden process, with emotions entwined with the social influence process. Effective leaders create situations and events that lead to positive emotional responses. Their effectiveness lies in the realisation that the achievement of goals comes about through the goodwill and support of their employees. This goodwill and support originates in the leaders seeing people as people, not another resource for deployment in support of the task. Undoubtedly, true leaders use integrated leadership competencies to move organizational processes and their employees forward - an exacting task, but nothing less must be expected from collegial leaders.

\section{AUTHOR INFORMATION}

Prakash Singh is a professor at the Nelson Mandela Metropolitan University in Port Elizabeth, South Africa. He is a NRF-rated researcher and a Fulbright scholar. His niche research areas of publication are organizational behaviour and social psychology. Professor Singh is the author of Innovative Strategies to Develop Better Schools and coauthor of Principal Leadership. He has also published widely in peer-reviewed journals and has presented numerous papers at international conferences. E-mail: Prakash.Singh@nmmu.ac.za.

Christopher Malizo Dali is a lecturer at the Nelson Mandela Metropolitan University in Port Elizabeth, South Africa. His Ph.D. focused on the emotional intelligence of school principals. Dr. Dali has presented several papers at conferences, has published articles in journals, and is the co-author of Principal Leadership. His niche areas of research include collegial leadership, emotional intelligence, and developing the work-integrated learning competencies of school leaders. E-mail: Chris.Dali@nmmu.ac.za.

\section{REFERENCES}

1. Abraham, R. (2000). The role of job control as a moderator of emotional dissonance and emotional intelligence: Outcomes relationships. The Journal of Psychology, 134: 169-189.

2. Alves, J. C., Manz, C. C., \& Butterfield, D. A. (2005). Developing leadership theory in Asia: The role of Chinese philosophy. International Journal of Leadership Studies, 1(1): 3-27.

3. Anand, R. \& UdayaSuriyan, G. (2010). Emotional intelligence and its relationship with leadership practices. International Journal of Business and Management, 5(2): 65-75.

4. Ayiro, L. P. (2009). An analysis of emotional intelligence and the performance of principals in selected schools in Kenya. Advances in Developing Human Resources, 11(6): 719-746. Retrieved from: http://adh.sagepub.com/content/11/6/719.

5. Barbuto, J. E. \& Burbach, M. E. (2006). The emotional intelligence of transformational leaders: A field study of elected officials. Journal of Social Psychology, 146(1): 51-64.

6. Bar-On, R. (1997). Bar-On emotional quotient inventory (EQ-i: A test of emotional intelligence. Toronto, Canada: Multi-Health Systems.

7. Bar-On, R. (2000). Emotional and social intelligence: Insights from the emotional quotient inventory (EQi). In R. Bar-On \& J. D. A. Parker (Eds.), Handbook of emotional intelligence. San Francisco: Jossey-Bass.

8. Baxter, J. \& Burden, P. (2008). Redefining doctoral programmes as work-integrated learning experience. World Association for Cooperative Education (WACE)/Australian Collaborative Education Network (ACEN) Asia Pacific Conference Proceedings. University of Technology, Sydney, Australia.

9. Burkman, A. (2010). The role of social, civic and political responsibility in educational leadership preparation programmes. The Connexions Project. Retrieved from: http://creativecommonc.org/licences/by/3.0/.

10. Calitz, L. (2002). Leadership for change in education: The South African perspective. In L. Calitz, O.L. Fuglestad \& L. Lillejord (Eds.), Leadership in education. Sandown: Heineman.

11. Catano, N. \& Stronge, J. H. (2007). What do we expect of school principals? Congruence between principal evaluation and performance standards. International Journal of Leadership in Education, 10(4): 
379-399.

12. Cooper, C. L. (1984). Improving interpersonal relations. London: Wilwood House.

13. Corey, G., Corey, M. S., \& Callanan, P. (1993). Issues and ethics in the helping professions. California: Brooks.

14. Crawford, M. (2007). Emotional coherence in primary school headship. Educational Management, Administration \& Leadership, 35(4): 521-534.

15. Dane, F. C. (1990). Research methods. California: Brooks.

16. Davies, D. \& Dodd, J. (2002). Qualitative research and the question of rigour. Qualitative Health Research, 12(2): 279-289.

17. Devers, K. J. \& Frankel, R. M. (2000). Study design in qualitative research: Sampling and data collection strategies. Education for Health: Change in Learning \& Practice, 13(2): 263-271.

18. Dulewicz, C., Young, M., \& Dulewicz, V. (2005). The relevance of emotional intelligence for leadership performance. The Journal of General Management, 30(3): 71-86.

19. Eames, C. \& Cates, C. (2004). Theories of learning in cooperative education. In R. K. Coll \& C. Eames (Eds.), International handbook for cooperative education: An international perspective of the theory, research and practice of work-integrated learning. Boston: World Association for Cooperative Education, Inc. and the Authors International Secretariat.

20. Ehigie, B. O. \& Ehigie, R. I. (2005). Applying qualitative methods in organisations: A note for industrial/organisational psychologists. The Qualitative Report, 10(3): 621-638.

21. Fer, S. (2004). Qualitative evaluation of emotional intelligence in-service programme for secondary school teachers. The Qualitative Report, 9(4): 562-588.

22. Gardenswartz, L., Cherbosque, J., \& Rowe, A. (2010). Emotional intelligence and diversity: A model for differences in the workplace. Journal of Psychological Issues in Organisational Culture, 1(1): 74-84.

23. Gardner, L. \& Stough, C. (2002). Examining the relationship between leadership and emotional intelligence in senior level managers. Leadership \& Organisational Development Journal, 23(2): 68-78.

24. Gilley, A., McMillan, H. S., \& Gilley, J. W. (2009). Organisational change and characteristics of leadership effectiveness. Journal of Leadership \& Organisational Studies, 16(1): 38-47.

25. George, J. M. (2000). Emotions and leadership: The role of emotional intelligence. Human Relations, 53: 1027-1041.

26. Goleman, D., Boyatzis, R., \& McKee, A. (2002). Primal leadership. Boston: Harvard Business School Press.

27. Groenewald, T. (2004). Towards a definition for cooperative education. In R.K. Coll \& C. Eames (Eds.), International handbook for cooperative education: An international perspective of theory, research, and practice of work-integrated learning. Boston: World Association for Cooperative Education (WACE).

28. Hang, T. T. (1999). Emotional intelligence and careers. Centre for Development of Teaching and Learning Brief, 2(1): 1-9.

29. Harris, L. (2006). Changing leadership paradigms and practices of doctoral students. American Association of School Administrators Journal of Scholarship and Practice, 5(2): 49-53.

30. Heiskanen, E., Jarvela, K., Pulliainen, A., Saastamoinen, M., \& Timonen, P. (2008). Qualitative research and consumer policy: FG discussions as a form of consumer participation. The Qualitative Report, 13(2): $152-172$.

31. Ivcevic, Z., Brackett, M. A., \& Mayer, J. D. (2007). Emotional intelligence and emotional creativity. Journal of Personality, 75(2): 199-235.

32. Ketelle, D. (2008). We really do not talk like this: Principals in dialogue. American Association of School Administrators Journal of Scholarship and Practice, 5(2): 49-53.

33. Lankshear, C. \& Knobel, M. (2004). A handbook for teacher research: From design to implementation. New York: Open University Press.

34. Lopes, P. L., Brackett, M. A., Nezlek, J. B., Schutz, A., Sellin, I., \& Salovey, P. (2004). Emotional intelligence and social interaction. Personality and Social Psychology Bulletin, 30(8): 1018-1034.

35. Luca, J. \& Tarricone, P. (2001). Does emotional intelligence affect successful teamwork? In G. Kennedy, M. Keppell, C. McNaught, \& T. Petrovic (Eds.), Meeting at crossroads. School of Multimedia. Retrieved from: http;//www.ascilite.org.au.elibrary.jcu.edu.au/conferences/melbourne0/pdf/paper/l

36. MacLean, M. (2006). Pedagogy and the university: Critical theory and practice. London: Continuum. 
37. Maxwell, L. F. (2010). Emotional intelligence: What works at work. Law Library Journal,102(1): 155-159.

38. Mayer, J. D. (2001). A field guide to emotional intelligence. In J. Ciarrochi, J. P. Forgas, \& J. D. Mayer (Eds.), Emotional intelligence in everyday life. Philadelphia: Psychology Press.

39. Mayer, J. D. \& Salovey, P. (1997). What is emotional intelligence? In P. Salovey \& D.J. Sluyter (Eds.), Emotional development and emotional intelligence. New York: Basic Books.

40. Mayer, J. D., Salovey, P., \& Caruso, D. R. (2004). Emotional intelligence: Theory, findings, and implications. Psychology Inquiry, 15(3): 197-215.

41. Mestry, R. \& Singh, P. (2007). Continuing professional development for principals: A South African perspective. South African Journal of Education, 27(3): 447-462.

42. Miles, M. B., \& Huberman, A. M. (1994). Qualitative data analysis: An expanded sourcebook. Thousand Oaks: Sage.

43. Morse, J. M. (1994). Critical issues in qualitative research methods, California: Sage.

44. Nokelainen, P. \& Ruohotie, P. (2006). Empirical analysis of the four-domain model of emotional leadership. Paper presented at European Conference on Educational Research (ECER), Geneva, Switzerland.

45. Ornstein, A. C., \& Hunkins, F. P. (2004). Curriculum, principles, and issues. London: Allyn \& Bacon.

46. Payne, H. J. (2005). Reconceptualising social skills in organisations: Exploring the relationship between communication competence, job performance, and supervisory roles. Journal of Leadership \& Organisational Studies, 11 (2): 63-77.

47. Prati, L. M., Liu, Y., Perrewe, P. L., \& Ferris, G. R. (2009). Emotional intelligence as moderator of the surface acting-strain relationship. Journal of Leadership \& Organisational Studies, 15(4): 368-380.

48. Rees, S. (2004). The new focus for teachers and unions. NUE Comment, 1: 7-8.

49. Saiz, I. (2009). Policy and practices note: Rights in recession? Challenges for economic and social rights enforcement in times of crisis. Journal of Human Rights Practice, 1(2): 277-293.

50. Salmon, G. L. (2008). The evolution of coaching in the US Federal Government. International Journal of Coaching in Organisations, 6(1): 7-17.

51. Sarros, A. M. \& Sarros, J. C. (2007). The first 100 days: Leadership challenges of a new CEO. Educational Management Administration \& Leadership, 35(3): 349-371.

52. Schutte, N. S., Malouff, J. M., Bobik, C., Coston, T. D., Greeson, C., Jedlicka, C., Rhodes, E., \& Wendorf, G. (2001). Emotional intelligence and interpersonal relations. Journal of Social Psychology, 141(4): 523537.

53. Singh, K. (2010). Developing human capital by linking emotional intelligence with personal competencies in Indian business organisations. International Journal of Business Science and Applied Management, 5(2): 29-42.

54. Singh, P. (2005). Use of the collegial leadership model of emancipation to transform traditional management practices in secondary schools. South African Journal of Education, 25(1): 11-18.

55. Singh. P. (2013). Transforming traditional bureaucratic management practices by employing the Collegial Leadership Model of Emancipation. International Business \& Economics Research Journal, 12(8): 953968.

56. Singh, P., Manser, P., \& Mestry, R. (2007). Importance of emotional intelligence in conceptualising collegial leadership in education. South African Journal of Education, 27(3): 541-563.

57. Stead, G. B. \& Struwig, F. W. (2001). Planning, designing and reporting research. Cape Town: Maskew Miller.

58. Stenbacka, C. (2001). Qualitative research requires quality concepts of its own. Management Decision, 39(7): 551-555.

59. Tennant, M. \& McMullen, C. (2008). The workplace as a site for learning: Challenges and possibilities. WACE/ACEN Asia Pacific Conference Proceedings. University of Technology, Sydney, Australia.

60. Yukl, G. A. (2002). Leadership in organisations. Englewood Cliffs, NJ: Prentice Hall. 


\section{NOTES}

